\title{
KINETIC AND MECHANISTIC FEATURES OF THE THIOLACTIC ACID OXIDATION BY CHROMIUM(VI) IN ACIDIC ENVIRONMENT
}

\author{
DANA MARIA SABOU ${ }^{a, *}$, IOAN BÂLDEA ${ }^{a}$
}

\begin{abstract}
Thiolactic acid, containing a reactive sulphydryl group, has been shown to easily reduce $\mathrm{Cr}(\mathrm{VI})$ and yield disulfide as oxidation product. The reaction was studied by the use of spectrophotometry. The spectral data as well as the kinetic information showed distinct evidence of the formation of an Sbonded $\mathrm{Cr}(\mathrm{VI})$-thiolactate intermediate that was subsequently followed by a somewhat slower, bimolecular redox process leading to the formation of the final products. The rate laws for these two stages have been determined, showing a complex dependence on substrate and hydrogen ion concentration. Small experimental Arrhenius activation energies for the two successive steps were also obtained. The involvement of paramagnetic $\mathrm{Cr}(\mathrm{V})$ species and that of some organic free radicals were evidenced by ESR and, the latter, also by initialization of polymerization. A reaction mechanism has been proposed, that leads to a rate law in convincing agreement with the experimental one.
\end{abstract}

Keywords: kinetics, redox, chromium VI, thiolactic acid

\section{INTRODUCTION}

The interest in the chemistry of sulphydryl compounds and thiyl radicals is derived from their involvement in a large number of processes in natural systems, including species present in the human body. On the other hand, chromium $(\mathrm{VI})$ is widely used in various industries and practical applications, however, with toxic effects for humans, that include carcinogenicity due to its conversion by intracellular reductants to more active species that initiate DNA damage [1-5]. Therefore, the understanding of the interaction mechanism

\footnotetext{
a Babeş-Bolyai University, Faculty of Chemistry and Chemical Engineering, 11 Arany Janos str., RO-400028, Cluj-Napoca, Romania.

*Corresponding author: dsabou@chem.ubbcluj.ro
} 
between $\mathrm{Cr}(\mathrm{VI})$ and sulphydryl compounds is of great importance, and while considerable research has been done in the field, it remains yet a topic of interest.

Mechanistically, $\mathrm{Cr}(\mathrm{VI})$ oxidations of organic compounds (alcohols, aldehydes, thiols, hydroxy- and mercapto- acids) or inorganic compounds (sulphite, phosphite, hypophosphite) proceed by inner-sphere and the first step is an equilibrium of the type $\mathrm{HCrO}_{4}^{-}+\mathrm{HX} \rightleftharpoons \mathrm{XCrO}_{3}^{-}+\mathrm{H}_{2} \mathrm{O}$ [6-13]. The condensation complex formed $\left(\mathrm{XCrO}_{3}^{-}\right)$further decomposes by transfer of electrons, this being often the rate determining step. Depending on the nature of the reducing agent and the molecularity of this electron transfer step, the number of electrons changed may vary from one [14,15] (to form $\mathrm{Cr}(\mathrm{V})$ ) to two [16-18] (yielding $\mathrm{Cr}(\mathrm{IV})$ ) or even three in some co-oxidations $[19,20]$. The involvement of the intermediate valence states $\mathrm{Cr}(\mathrm{V})$ and $\mathrm{Cr}(\mathrm{IV})$, both also oxidizing agents, as well as that of other very reactive intermediates, such as organic radicals, brings about complicated reaction schemes [6]. When thiols or thiol acids are the reducing agents, the sulphydryl group is involved and the sulphur atom is the one to suffer a change in the oxidation state [21]. Rate laws of first-order (in the condensed complex) or second order (first order in the complex and first order in the substrate) have been reported [6].

The study of the thiolactic acid oxidation by chromium(VI) falls in line with the long lasting interest of our group in the kinetics of alcohols and thiols homogeneous oxidation reactions.

Early tests showed a rapid change of color from yellow to red-brown to take place already during the mixing of some acidic solutions of the two reactants, which than paled quite fast as well, as time elapsed. This clearly indicated that the red-brown species is an intermediate formed during the reaction process and that the reaction has two photometrically distinguishable stages, but it also suggested that the set of experimental conditions under which the reaction can be studied for reliable mechanistic insight is somewhat restrictive. The difficulties have to do with the quite fast overall rate of the process, as well as with the quite comparable relative rates of the two observable stages. These make the reaction only borderline approachable by either batch or fast-reaction techniques alone.

The findings of a stopped-flow approach aimed at explaining the formation of the condensed intermediate complex have been previously reported [22]. The stopped-flow technique was considered better suited for the study of the beginning of the reaction, as it ensures the fast and reproducible mixing of the reactants. However, with spectrophotometry employed as the detection method, the usually small path length of the mixing chamber $(0.336 \mathrm{~cm}$ in our case) imposed the use of $\mathrm{Cr}(\mathrm{VI})$ (the monitored species) in higher 
concentrations than those accessible under a batch approach, when cuvettes of a length at choice can be used. This in turn enhanced the overall rate and subsequently narrowed the range of thiolactic acid and $\mathrm{H}^{+}$concentrations that could be spanned.

To gain more insight on the reaction progress, a batch setup was tried out for further study of the reaction. The purpose of this paper is to report the results concerning the kinetics of both the formation and decay of the intermediate, obtained under batch conditions and by the use of spectrophotometry as the detection technique, and also to suggest a plausible overall reaction mechanism. To this end, information of extra-kinetic type was gathered as well, to clarify the matter of the involvement of further reaction intermediates.

\section{RESULTS AND DISCUSSION}

\section{Reaction stoichiometry}

In a spectrophotometric approach, mixtures containing increasing molar ratios of thiolactic acid (abbreviated here as $\mathrm{RSH}$ ) to $\mathrm{Cr}(\mathrm{VI})$ were prepared and the remaining absorbance was measured at $350 \mathrm{~nm}$, after the reaction has been completed. The measured absorbance was almost zero for the ratios of 3 to 1 and higher, meaning that all $\mathrm{Cr}(\mathrm{VI})$ has reacted. This is in agreement with many literature data concerning oxidations of mono-thiols $[6,10]$. However, for the lower ratios the behavior was not linear, raising the question of whether further oxidation to oxygenated products might take place.

To settle this, we resorted to iodometrical titration. Six reaction mixtures were prepared, all with $\mathrm{RSH}$ in excess over $\mathrm{Cr}(\mathrm{VI})$, and allowed to react to completion. The concentrations of the two reactants were in this case 10 times higher therefore completion was reached within less than one minute. The mean of these experiments showed, indeed, a total of $3.09 \pm$ $0.03 \mathrm{~mol}$ of thiolactic acid to react with $1 \mathrm{~mol}$ of $\mathrm{Cr}(\mathrm{VI})$.

Based on the above, the overall stoichiometry can be qualitatively schematized as in equation (1):

$$
\begin{gathered}
6 \mathrm{CH}_{3} \mathrm{CH}(\mathrm{COOH}) \mathrm{SH}+2 \mathrm{HCr}^{\mathrm{VI}} \mathrm{O}_{4}^{-}+8 \mathrm{H}^{+} \longrightarrow \\
\longrightarrow 3\left(\mathrm{CH}_{3} \mathrm{CH}(\mathrm{COOH}) \mathrm{S}\right)_{2}+2 \mathrm{Cr}^{\mathrm{III}}+8 \mathrm{H}_{2} \mathrm{O}
\end{gathered}
$$

\section{Electronic spectra giving evidence of the intermediate}

Electronic spectra of $\mathrm{HCrO}_{4}^{-}$and thiolactic acid, as well as some qualitative ones of a reaction mixture, collected at various time intervals, are presented in Figure 1. It is clear that, as compared to $\mathrm{HCrO}_{4}{ }^{-}$, the mixture 
exhibits lower absorbance at $350 \mathrm{~nm}$, but a more pronounced absorption band around $420 \mathrm{~nm}$. The progress of the reaction can be followed at either of these wavelengths, yet the absorbance of the intermediate interferes with that of the reactant at both of them.

The shift of the charge-transfer maximum from 350 in $\mathrm{HCrO}_{4}^{-}$to 420 $\mathrm{nm}$ in the mixture argues the change of an oxygen ligand of $\mathrm{Cr}(\mathrm{VI})$ with a sulphur one, thus the formation of a condensed thiolato-chromate compound of esteric type. This takes place according to the following equilibria:

$$
\begin{gathered}
\mathrm{CH}_{3} \mathrm{CH}(\mathrm{COOH}) \mathrm{SH}+\mathrm{HOCrO}_{3}^{-} \rightleftharpoons \mathrm{CH}_{3} \mathrm{CH}(\mathrm{COOH}) \mathrm{SCrO}_{3}^{-}+\mathrm{H}_{2} \mathrm{O} \\
\mathrm{CH}_{3} \mathrm{CH}(\mathrm{COOH}) \mathrm{SH}+\mathrm{HOCrO}_{3}^{-}+\mathrm{H}^{+} \rightleftharpoons \mathrm{CH}_{3} \mathrm{CH}(\mathrm{COOH}) \mathrm{SCrO}_{3}^{-}+\mathrm{H}_{3} \mathrm{O}^{+}
\end{gathered}
$$

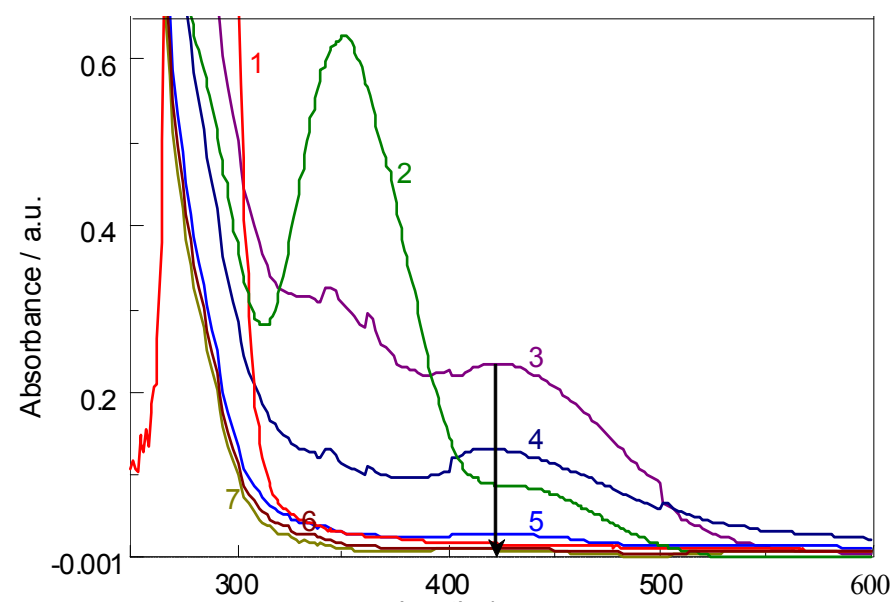

Figure 1. Spectra of the reactants and of the reaction mixture: $1-[\mathrm{RSH}]=0.1 \mathrm{M}$; $2-[\mathrm{Cr}(\mathrm{VI})]=7.22 \cdot 10^{-5} \mathrm{M} ; 3-7$ - reaction mixture at some time intervals $(\mathrm{T}=293 \mathrm{~K}$, $\left.\mu=0.5 \mathrm{M} ;[\mathrm{RSH}]=2.67 \cdot 10^{-3} \mathrm{M},[\mathrm{Cr}(\mathrm{VI})]_{0}=6.67 \cdot 10^{-5} \mathrm{M},\left[\mathrm{H}^{+}\right]=3.16 \cdot 10^{-3} \mathrm{M}\right)$.

\section{Reaction kinetics}

Taking into account the equilibria involving $\mathrm{Cr}(\mathrm{VI})[23,24]$ species it is possible to chose such conditions of its concentration $\left(10^{-5}-10^{-4} \mathrm{M}\right)$, acidity $\left(\mathrm{pH} 1-5, \mathrm{HClO}_{4}\right)$ and ionic strength $\left(<1 \mathrm{M}, \mathrm{NaClO}_{4}\right)$ to ensure that $\mathrm{HCrO}_{4}^{-}$ is the vastly predominant species in the solution. Also, pseudo-first order conditions were ensured, with $\mathrm{Cr}(\mathrm{VI})$ always as the limiting component $\left(6.67 \cdot 10^{-5} \mathrm{M}\right)$ and the concentrations of $\mathrm{RSH}$ and $\mathrm{H}^{+}$in high excess. In this arrangement, the reaction reaches accomplishment within several minutes. The absorbance evolution during time at both $350 \mathrm{~nm}$ and $420 \mathrm{~nm}$ is exemplified in Figure 2. 


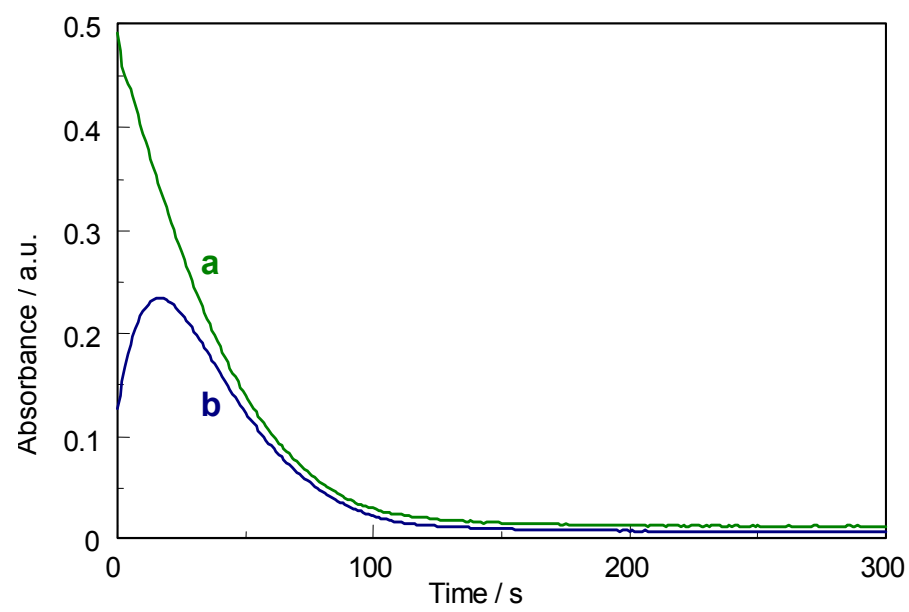

Figure 2. Experimental kinetic curves recorded at $350 \mathrm{~nm}$ (a) and at $420 \mathrm{~nm}$ (b) $\left([\mathrm{Cr}(\mathrm{VI})]_{0}=6.67 \cdot 10^{-5} \mathrm{M},\left[\mathrm{H}^{+}\right]=3.16 \cdot 10^{-2} \mathrm{M},[\mathrm{RSH}]=1.33 \cdot 10^{-3} \mathrm{M}, \mathrm{T}=293 \mathrm{~K}, \mu=0.5 \mathrm{M}\right)$.

The kinetic curves at $350 \mathrm{~nm}$ show a continuous decay, while the recordings at $420 \mathrm{~nm}$ clearly display the biphasic shape characteristic of two consecutive steps. The differences in shape are most likely owing only to the differences in the molar absorptivities. The wavelength chosen to follow the reaction extensively was $420 \mathrm{~nm}$.

The following reaction sequence has been considered:

$$
\begin{aligned}
& R+R S H\left(+H^{+}\right) \rightleftharpoons I\left(+H^{+}\right) \quad \mathrm{k}_{1}, \mathrm{k}_{-1} \\
& I(+R S H)\left(+H^{+}\right) \longrightarrow P\left(+H^{+}\right) \quad \mathrm{k}_{2}
\end{aligned}
$$

where the parentheses are meant to suggest that the respective species may or may not partake in the process.

Under the excess concentrations of $\mathrm{RSH}$ and $\mathrm{H}^{+}$, this simplifies greatly, to:

$$
R \stackrel{k_{10 b s}}{\longrightarrow} I \stackrel{k_{2 o b s}}{\longrightarrow} P
$$

which is a sequence of two apparent first order reactions, described by an integrated rate law containing two exponential terms.

Written in terms of absorbance, equation (6) takes the form (eq. 7):

$$
A-A_{\infty}=[R]_{0} I\left\{\varepsilon_{R}+\frac{k_{2 o b s} \varepsilon_{P}-k_{1 o b s} \varepsilon_{I}}{k_{10 b s}-k_{2 o b s}}\right\} e^{-k_{10 b s} t}+[R]_{0} I\left\{\frac{k_{1 o b s}\left(\varepsilon_{I}-\varepsilon_{P}\right)}{k_{10 b s}-k_{2 o b s}}\right\} e^{-k_{20 b s} t}
$$


where $A$ and $A_{\infty}$ stand for the actual and final absorbances, $/$ is the path length of the cell and $\varepsilon_{R}, \varepsilon_{1}$, and $\varepsilon_{P}$ are the molar absorptivities of the reactant $R$, intermediate $\mathrm{I}$, and product $\mathrm{P}$.

Since the pre-exponential terms are composed of constants, they can be combined under singular notations, to give a simpler equation:

$$
A-A_{\infty}=\gamma_{1} e^{-k_{10 b s} t}+\gamma_{2} e^{-k_{20 b s} t}
$$

\section{Data processing}

One milestone in extracting useful information was the processing of the kinetic curves. Three possible ways were tested, one based on sequential linear regression (over appropriate parts of the curve) and the other two being variants of non-linear regression. The detailed discussion and comparison between them made the subject of a previous report [25]. Here, a brief account will be given.

\section{Method A - Sequential linear regression}

When the condition $k_{10 b s}>5 k_{2 o b s}$ is fulfilled [26], at "long reaction times" (high conversions) the first step of the reaction is accomplished and only the second step proceeds. In equation (8), the first exponential term vanishes and it is possible to determine $\mathrm{k}_{2 \mathrm{obs}}$ and $\gamma_{2}$ from the linear logarithmic form (eq. 9):

$$
\ln \left(A-A_{\infty}\right)=\ln \gamma_{2}-k_{2 o b s} t
$$

In the beginning of the process, the formation of the intermediate prevails. Hence, for "short reaction times" (low conversions), with the now known $k_{2 o b s}$ and $\gamma_{2}$, equation (10) can be derived, which permits the determination of $\gamma_{1}$ and $k_{10 b s}$.

$$
\ln \left(A-A_{\infty}-\gamma_{2} e^{-k_{2 o b s} t}\right)=\ln \gamma_{1}-k_{\text {lobs }} t
$$

The handling of the data by using the Microsoft Excel program showed that, indeed, for "long times" (after more than $90 \%$ of reaction) the behavior is linear with $\mathrm{R}^{2}$ between 0.9925 and 0.9990 . The plots according to equation (10) were also linear at short times after mixing $\left(R^{2} \in[0.9911 \div 0.9999]\right)$.

However, it became obvious that the condition $k_{10 b s}>5 k_{2 o b s}$ is not fulfilled. In such case, the accuracy of the $k_{\text {obs }}$ values is expected to suffer - more so that of the $k_{10 b s}$ values, which would also be affected by the errors in $k_{2 o b s}$. 
KINETIC AND MECHANISTIC FEATURES OF THE THIOLACTIC ACID OXIDATION BY CHROMIUM(VI) IN ...

\section{Method B - non-linear regression}

Furthermore, the experimental curves were subjected to non-linear fitting with an equation derived from the same reaction model. For this, equation (7) was written in the form below (eq.11), which satisfies the requirements of the software used.

$$
\begin{array}{r}
Y=F_{1} \cdot e^{\left(-k_{10 b s}\left(X+X_{0}\right)\right)}+F_{2} \cdot e^{\left(-k_{2 o b s}\left(X+X_{0}\right)\right)}+Y_{0} \\
\text { with } \quad F_{1}=0.0003335\left(\varepsilon_{R}-\frac{\varepsilon_{I} \cdot k_{1 o b s}}{k_{10 b s}-k_{2 o b s}}+\frac{\varepsilon_{P} \cdot k_{2 o b s}}{k_{1 o b s}-k_{2 o b s}}\right) \\
\text { and } \quad F_{2}=0.0003335 \cdot k_{\text {lobs }}\left(\frac{\varepsilon_{I}-\varepsilon_{P}}{k_{1 o b s}-k_{2 o b s}}\right)
\end{array}
$$

and where $\mathrm{Y}=\mathrm{A}$ (absorbance), $\mathrm{X}=\mathrm{t}$ (time), $\mathrm{X}_{0}=$ time delay at the start of data acquisition, $Y_{0}=a$ correction factor for base line (the translation of the curve along the $\mathrm{Y}$ axis, including $\left.\mathrm{A}_{\infty}\right), 0.0003335=[\mathrm{Cr}(\mathrm{VI})] \mathrm{l} \cdot \mathrm{l}$, and $\mathrm{k}_{1 \mathrm{obs}}, \mathrm{k}_{2 \mathrm{obs}}$, $\varepsilon_{R}, \varepsilon_{l}$ and $\varepsilon_{\mathrm{P}}$ all are as described above.

Two approaches were tested: fitting the curves one by one or fitting groups of curves pertaining to various sets of concentrations. While valuable as a checkup method, the multiple curve fitting will give biased results if a curve affected by large errors happens to be part of the group, hence the single curve fitting was preferred. This was done by the program TableCurve 2D 5.0 (Systat Software). It operates by successive iterations varying the specified parameters in order to get the best fit.

Details of the initialization procedure and the limitations are given elsewhere [25]. An important mention is that the estimates of the input values for the apparent rate constants were based on the results provided by method $A$. From this point of view, it can be said that method $B$ was used to refine the results of method $A$.

With good estimates for the input values, very good fits were obtained. The $k_{\text {obs }}$ values obtained by method $B$ were in general comparable to those of method $A$, with method $A$ appearing to have somewhat overestimated $k_{10 b s}$.

The method $B$ should give more accurate results, in the least because the $k_{1 \text { obs }}$ and $k_{2 \text { obs }}$ values also satisfy the $F_{1}$ and $F_{2}$ expressions, a fact that was disregarded in the case of method $A$. However, it appears that methods $A$ and $B$ are best used in tandem, at least for such cases as the one at hand, with two consecutive steps of comparable rates.

The $k_{o b s}$ values used for the kinetic interpretation were as obtained from the nonlinear fitting of single curves (method B) at $420 \mathrm{~nm}$. Tables 1 and 2 show averaged numbers of the three to seven runs (as given in parentheses) performed for each set of concentrations. However, the further kinetic interpretations are based on plots containing the individual values of the two constants. 
Table 1. Average values of $\mathrm{k}_{1 \mathrm{obs}}$ and $\mathrm{k}_{2 \mathrm{obs}}$, obtained with $\left[\mathrm{HCrO}_{4}^{-}\right]=6.67 \cdot 10^{-5} \mathrm{M}$ and various $[\mathrm{RSH}]$, at three $\mathrm{H}^{+}$concentrations ( $\mathrm{T}=293 \mathrm{~K}, \mu=0.5 \mathrm{M}, \lambda=420 \mathrm{~nm}$ ).

\begin{tabular}{|c|c|c|c|c|c|c|}
\hline \multirow{3}{*}{$\begin{array}{c}10^{3} \cdot[\mathrm{RSH}] \\
(\mathrm{M})\end{array}$} & \multicolumn{3}{|c|}{$\mathrm{k}_{1 \mathrm{obs}}\left(\mathrm{s}^{-1}\right)$} & \multicolumn{3}{|c|}{$\mathrm{k}_{\text {2obs }}\left(\mathrm{s}^{-1}\right)$} \\
\hline & \multicolumn{6}{|c|}{ 102. $\left[\mathrm{H}^{+}\right](\mathrm{M})$} \\
\hline & 3.12 & 0.98 & 0.31 & 3.12 & 0.98 & 0.31 \\
\hline 1.33 & $0.051(4)$ & $0.045(4)$ & $0.029(3)$ & $0.048(4)$ & $0.032(4)$ & $0.028(3)$ \\
\hline 1.67 & $0.070(4)$ & $0.043(4)$ & $0.034(3)$ & $0.057(4)$ & $0.040(4)$ & $0.033(3)$ \\
\hline 2.66 & $0.086(4)$ & $0.060(4)$ & $0.055(6)$ & $0.066(4)$ & $0.052(4)$ & $0.050(6)$ \\
\hline 3.33 & $0.111(7)$ & $0.076(4)$ & $0.067(6)$ & $0.088(7)$ & $0.064(4)$ & $0.059(6)$ \\
\hline 4.00 & $0.130(4)$ & $0.098(5)$ & $0.079(4)$ & $0.101(4)$ & $0.074(5)$ & $0.071(4)$ \\
\hline 5.00 & 0.179 (3) & $0.113(3)$ & $0.094(3)$ & $0.100(3)$ & $0.079(3)$ & $0.084(3)$ \\
\hline 5.33 & $0.182(4)$ & $0.116(4)$ & $0.100(4)$ & $0.129(4)$ & $0.083(4)$ & $0.091(4)$ \\
\hline 6.66 & $0.216(4)$ & $0.125(4)$ & $0.126(3)$ & $0.148(4)$ & $0.098(4)$ & $0.110(3)$ \\
\hline 8.00 & $0.253(4)$ & $0.160(4)$ & $0.146(3)$ & $0.177(4)$ & $0.102(4)$ & $0.125(3)$ \\
\hline 9.99 & & & $0.185(6)$ & & & $0.148(6)$ \\
\hline
\end{tabular}

Table 2. Average values of $\mathrm{k}_{10 b s}$ and $\mathrm{k}_{2 \mathrm{obs}}$, obtained with $\left[\mathrm{HCrO}_{4}^{-}\right]=6.6710^{-5} \mathrm{M}$ and various $\left[\mathrm{H}^{+}\right]$, at three $\mathrm{RSH}$ concentrations $(\mathrm{T}=293 \mathrm{~K}, \mu=0.5 \mathrm{M}, \lambda=420 \mathrm{~nm})$.

\begin{tabular}{|c|c|c|c|c|c|c|}
\hline & \multicolumn{5}{|c|}{$\mathrm{k}_{1 \text { obs }}\left(\mathrm{s}^{-1}\right)$} & \multicolumn{3}{c|}{$\mathrm{k}_{2 \text { obs }}\left(\mathrm{s}^{-1}\right)$} \\
\hline $\begin{array}{c}10^{2} \cdot\left[\mathrm{H}^{+}\right] \\
(\mathrm{M})\end{array}$ & 5.00 & 3.33 & 1.67 & 5.00 & 3.33 & 1.67 \\
\hline 0.13 & & & $0.033(3)$ & & & $0.030(3)$ \\
\hline 0.17 & $0.089(4)$ & & & $0.065(4)$ & & \\
\hline 0.19 & & & $0.033(4)$ & & & $0.031(4)$ \\
\hline 0.23 & $0.093(3)$ & & & $0.066(3)$ & & \\
\hline 0.29 & & $0.077(3)$ & & & $0.047(3)$ & \\
\hline 0.31 & $0.094(3)$ & $0.067(6)$ & $0.034(3)$ & $0.084(3)$ & $0.059(6)$ & $0.033(3)$ \\
\hline 0.33 & & $0.075(4)$ & $0.036(4)$ & & $0.052(4)$ & $0.033(4)$ \\
\hline 0.35 & $0.104(4)$ & & & $0.074(4)$ & & \\
\hline 0.43 & & $0.078(3)$ & & & $0.052(3)$ & \\
\hline 0.51 & & & $0.039(4)$ & & & $0.035(4)$ \\
\hline 0.53 & $0.097(3)$ & & & $0.074(3)$ & & \\
\hline 0.65 & & $0.076(3)$ & & & $0.054(3)$ & \\
\hline 0.79 & & $0.077(3)$ & & & $0.054(3)$ & \\
\hline 0.98 & $0.113(3)$ & $0.076(4)$ & $0.043(4)$ & $0.079(3)$ & $0.064(4)$ & $0.040(4)$ \\
\hline 1.29 & & $0.095(4)$ & & & $0.058(4)$ & \\
\hline 1.60 & $0.119(5)$ & $0.111(3)$ & $0.052(4)$ & $0.090(5)$ & $0.060(3)$ & $0.047(4)$ \\
\hline 1.97 & & $0.105(3)$ & & & $0.075(3)$ & \\
\hline 2.51 & $0.142(4)$ & $0.121(4)$ & $0.060(4)$ & $0.095(4)$ & $0.080(4)$ & $0.052(4)$ \\
\hline 3.12 & $0.179(3)$ & $0.111(7)$ & $0.070(4)$ & $0.100(3)$ & $0.088(7)$ & $0.057(4)$ \\
\hline 3.93 & $0.193(4)$ & & $0.075(4)$ & $0.114(4)$ & & $0.067(4)$ \\
\hline 5.01 & & $0.132(4)$ & & & $0.120(4)$ & \\
\hline 6.24 & $0.252(3)$ & $0.155(3)$ & $0.095(4)$ & $0.135(3)$ & $0.131(3)$ & $0.085(4)$ \\
\hline 7.93 & $0.277(3)$ & $0.195(4)$ & $0.107(3)$ & $0.156(3)$ & $0.139(4)$ & $0.093(3)$ \\
\hline 9.84 & $0.304(3)$ & $0.233(3)$ & $0.119(3)$ & $0.215(3)$ & $0.175(3)$ & $0.108(3)$ \\
\hline
\end{tabular}


KINETIC AND MECHANISTIC FEATURES OF THE THIOLACTIC ACID OXIDATION BY CHROMIUM(VI) IN ...

\section{Kinetic interpretation}

Having established that the process consists of two observable steps, the apparent first-order rate constants for each step are functions of the reaction conditions (excess $\mathrm{RSH}$ concentration, acidity, temperature and ionic strength).

\section{Intermediate formation}

As the concentrations of the organic substrate and the mineral acid are in large excess, the $\mathrm{k}_{10 b s}$ rate coefficients (dimensions $\mathrm{s}^{-1}$ ) correspond to first order in $\mathrm{HCrO}_{4}^{-}$, which is the limiting reactant. Based on equation (4), taking into account both directions of the equilibrium, $\mathrm{k}_{1 \text { obs }}$ can be written as

$$
k_{\text {lobs }}=k_{1}[R S H]_{0}^{a}\left[H^{+}\right]_{0}^{b}+k_{-1}\left[H^{+}\right]_{0}^{b}
$$

To obtain the partial orders with respect to $\mathrm{RSH}(\mathrm{a}) \mathrm{Or}^{+}(\mathrm{b})$, we first assume that in the beginning of the reaction, the first term prevails. Making use of log - log plots, the partial orders can be assessed. At constant acidity, the slope of the regression line will give the reaction order with respect to $\mathrm{RSH}$, whose excess was varied. Conversely, at constant excess of $\mathrm{RSH}$ and with the mineral acid varied, the order with respect to $\mathrm{H}^{+}$will be found. Figure 3 illustrates those plots.

The figure shows a linear behavior when [RSH] was varied, giving an integer order of 1 , and a curve when varying $\left[\mathrm{H}^{+}\right]$. At low acid concentration, the order with respect to hydrogen ion is near zero and increases as the concentration of the mineral acid is raised. This behavior is systematic within all experimental conditions employed (various excesses of $\mathrm{RSH}$ and various temperatures). Hence, the reaction order in $\mathrm{H}^{+}$is fractional between zero and one, with an increasing trend as the acidity is increased.
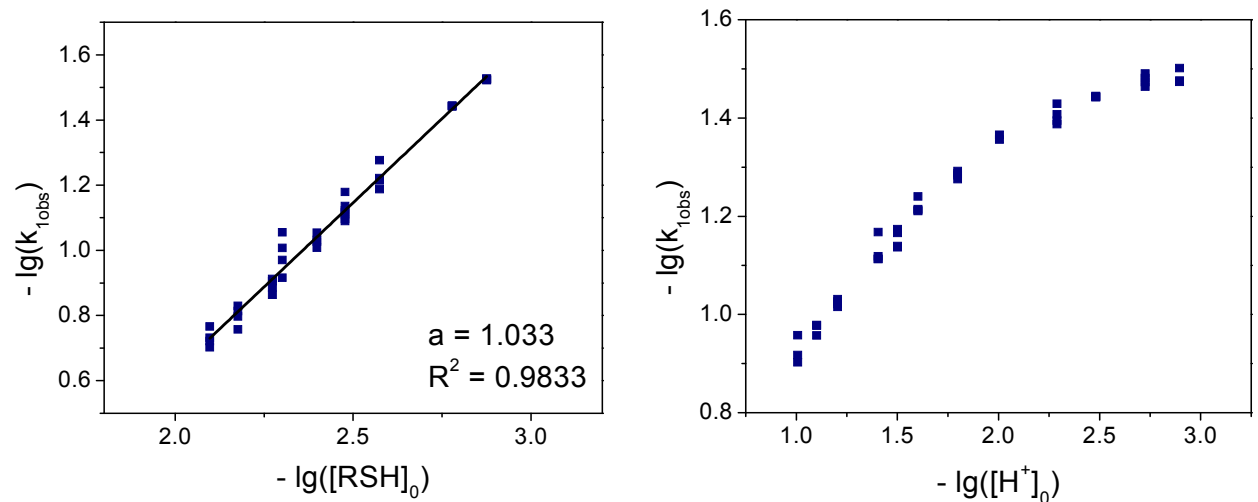

Figure 3. $\mathrm{Log}-\log$ plots to determine the partial orders with respect to $\mathrm{RSH}$ (at $\left.\left[\mathrm{H}^{+}\right]=0.0312 \mathrm{M}\right)$ and to $\mathrm{H}^{+}($at $[\mathrm{RSH}]=0.0050 \mathrm{M})$ for the intermediate formation. 
From a mechanistic point of view, this result can be interpreted by the intervention of two parallel reaction paths, one of zeroth order, and one of first order in $\mathrm{H}^{+}$, their relative importance depending on the range of acid concentration.

This outcome is in good agreement with that obtained by us in the previous work that dealt with the buildup of the intermediate in this reaction by means of a stopped-flow experimental approach and using the initial rates method $\left(\mathrm{n}_{\mathrm{Cr}(\mathrm{VI})}=1.07 \pm 0.08 ; \mathrm{n}_{\mathrm{RSH}}=1.02 \pm 0.07 ; \mathrm{n}_{\mathrm{H}+}=0.67 \pm 0.06\right)$ [22].

The conclusion to be drawn from these facts and the microreversibility principle is that the apparent first-order rate constant for the intermediate formation should be written as a sum of the two parallel paths:

$$
k_{\text {lobs }}=\left(k_{1}^{0}[R S H]+k_{-1}^{0}\right)+\left(k_{1}^{H}\left[H^{+}\right][R S H]+k_{-1}^{H}\left[H^{+}\right]\right)
$$

To evaluate the rate constants, the data were analyzed by plotting $\mathrm{k}_{1 \mathrm{obs}}$ as a function of excess thiol at constant acidity and as a function of acidity at constant thiol concentration. The graphs in Figures 4 and 5 were obtained.

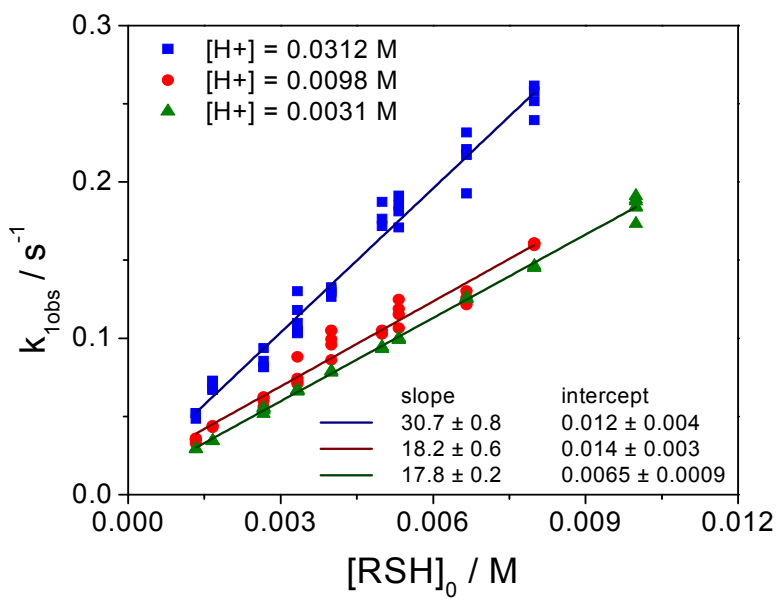

Figure 4. Linear dependence of $\mathrm{k}_{10 b s}$ on $[\mathrm{RSH}] 0$, with the slope $\mathrm{k}_{1}{ }^{0}+\mathrm{k}_{1}{ }^{\mathrm{H}}\left[\mathrm{H}^{+}\right]$.

The intercepts in Figure 4 are slightly positive (statistically different from zero) but affected by large errors. In theory, they might represent the $k_{-1}^{0}+k_{-1}^{H}\left[H^{+}\right]$contribution to the apparent first-order rate constant. The slope is the $k_{1}^{0}+k_{1}^{H}\left[H^{+}\right]_{0}\left(\mathrm{M}^{-1} \mathrm{~s}^{-1}\right)$ term in $\mathrm{k}_{10 b s}$. From the slopes of the lines in Figure 4, rate constants $\mathrm{k}_{1}{ }^{0}=(15 \pm 2) \mathrm{M}^{-1} \mathrm{~s}^{-1}$ and $\mathrm{k}_{1}{ }^{\mathrm{H}}=(5 \pm 1) \cdot 10^{2} \mathrm{M}^{-2} \mathrm{~s}^{-1}$ were obtained for the formation of the intermediate. 


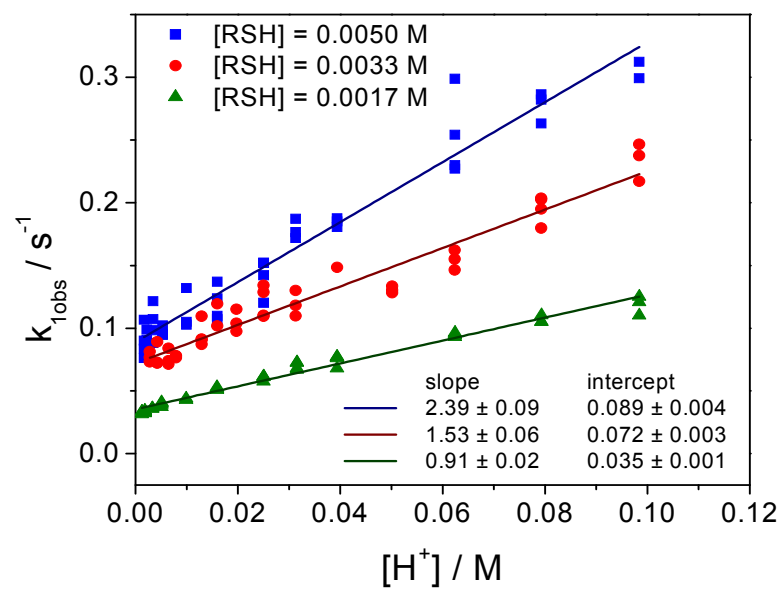

Figure 5. Linear plots of $\mathrm{k}_{10 b s}$ as a function of $\left[\mathrm{H}^{+}\right]$.

From the graph in Figure 5, with the intercepts differing from zero, it is obvious that there is a term of zeroth order with respect to $\mathrm{H}^{+}$. The same feature was observed upon different conditions of temperature. The slopes of the straight lines correspond to a process first-order in $\mathrm{H}^{+}$. The linear regression parameters yield values of $\mathrm{k}_{1}{ }^{0}=(16 \pm 3) \mathrm{M}^{-1} \mathrm{~s}^{-1}$ and $\mathrm{k}_{1} \mathrm{H}^{\mathrm{H}}=(4.4 \pm 0.6) \cdot 10^{2} \mathrm{M}^{-2} \mathrm{~s}^{-1}$, in fairly good agreement with those obtained from the effect of thiolactic acid concentration.

\section{Kinetics of the redox process (decay of the intermediate).}

In order to determine reaction orders with respect to the reactive species, the apparent first-order rate constants $\mathrm{k}_{20 b s}$ were used as dependent on the excess concentration of thiolactic acid or hydrogen ion concentration. Graphs of the type exemplified in Figure 6 below were obtained under various conditions.

In the case of the organic substrate, the graphs were linear to a good approximation and a fractional order between zero and one was obtained in all cases. This observation can be interpreted as the occurrence of two competing processes, one of zeroth and the other of first order in $\mathrm{RSH}$. From a mechanistic point of view this could be considered as a monomolecular decomposition of the intermediate, to form $\mathrm{Cr}(\mathrm{V})$ and a thiyl free radical $\mathrm{RS}^{*}$, along with a bimolecular process involving the complex and another $\mathrm{RSH}$ molecule, yielding the disulfide and $\mathrm{Cr}(\mathrm{IV})$ in a bi-equivalent electron transfer. On the other hand, the fractional order can be viewed as an expression of the one-plus form $[27,28]$, as suggested by the presence of the pre-equilibrium of intermediate formation. 

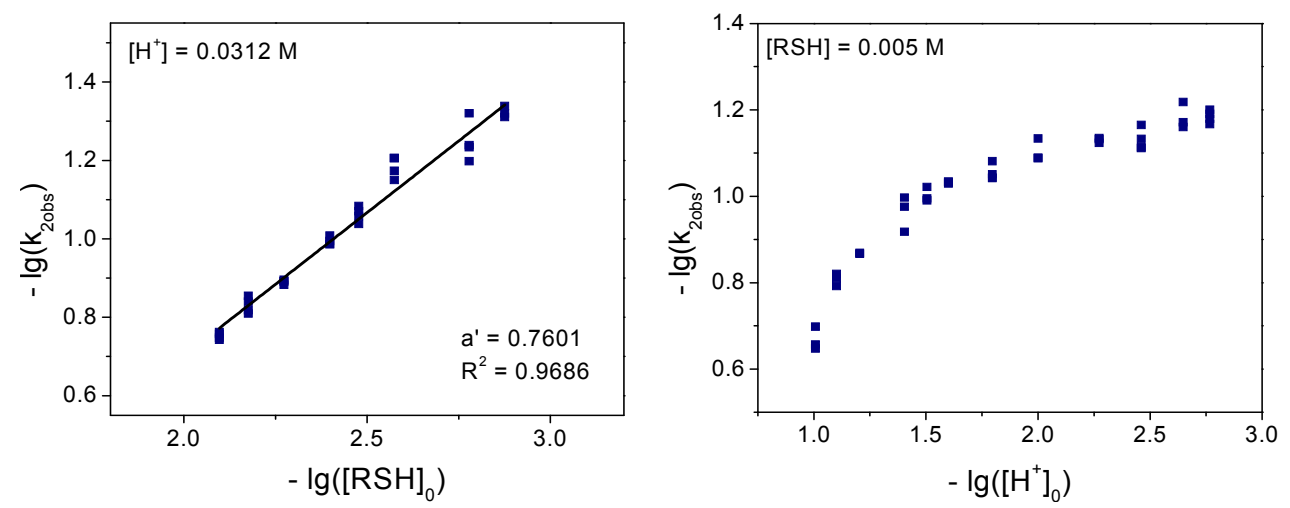

Figure 6. Log-log plots to determine the partial orders with respect to $\mathrm{RSH}$ and $\mathrm{H}^{+}$for the decay of the intermediate.

In the case of the involvement of hydrogen ions, once again a fractional order of less than 1 was found, increasing with rising acidity, as in the case of formation of the intermediate $\mathrm{RSCrO}_{3}{ }^{-}$. These facts can also be interpreted by two parallel paths or by a one-plus dependence.

Hence, there are four possibilities to describe the intermediate decay, governed by the following equations:

1) 4 parallel steps:

$$
k_{2 o b s}=k_{2}^{0}+k_{2}^{H}\left[H^{+}\right]+k_{3}^{0}[R S H]+k_{3}^{H}[R S H]\left[H^{+}\right]
$$

2) 2 parallel steps (with or without $\mathrm{H}^{+}$) and a pre-equilibrium effect on $\mathrm{RSH}$

$$
k_{2 o b s}=\left(k_{2}^{0}+k_{2}^{H}\left[H^{+}\right]\right) \frac{\alpha[R S H]}{1+\beta[R S H]}
$$

3) 2 parallel steps (with or without a second $\mathrm{RSH}$ ) and a pre-equilibrium effect on $\mathrm{H}^{+}$

$$
k_{2 o b s}=\left(k_{2}^{H}+k_{3}^{H}[R S H]\right) \frac{\alpha^{\prime}\left[H^{+}\right]}{1+\beta^{\prime}\left[H^{+}\right]}
$$

4) pre-equilibrium effect on both $\mathrm{RSH}$ and $\mathrm{H}^{+}$

$$
k_{2 o b s}=\frac{\alpha^{\prime \prime}\left[H^{+}\right][R S H]}{1+\beta^{\prime \prime}[R S H]+\gamma^{\prime \prime}\left[H^{+}\right]}
$$

The equations (17) to (19) are of one-plus type. Equations (18) and (19) stipulate a decreasing effect of $\mathrm{H}^{+}$which was not found experimentally. 
Equations (16) and (17) imply that a plot of $k_{2 o b s}$ as a function of the acidity should yield a line with some positive intercept. This is indeed the case, as Figure 7 clearly demonstrates.

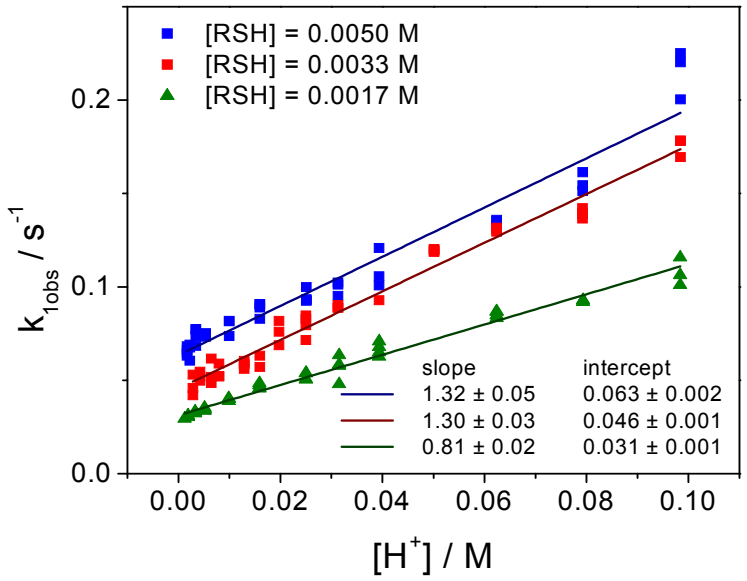

Figure 7. Linear dependence of $\mathrm{k}_{2 \mathrm{obs}}$ on $\left[\mathrm{H}^{+}\right]$.

On the other hand, for the dependence of $\mathrm{k}_{2 \mathrm{obs}}$ on the organic substrate, equation (17) predicts a decreasing effect of $\mathrm{RSH}$, meaning a curved shape with the gradient diminishing as the RSH concentration is increased. Conversely, an increasing effect of RSH would validate the linear equation (16). As shown in Figure 8, the behavior predicted by equation (17) was obtained.

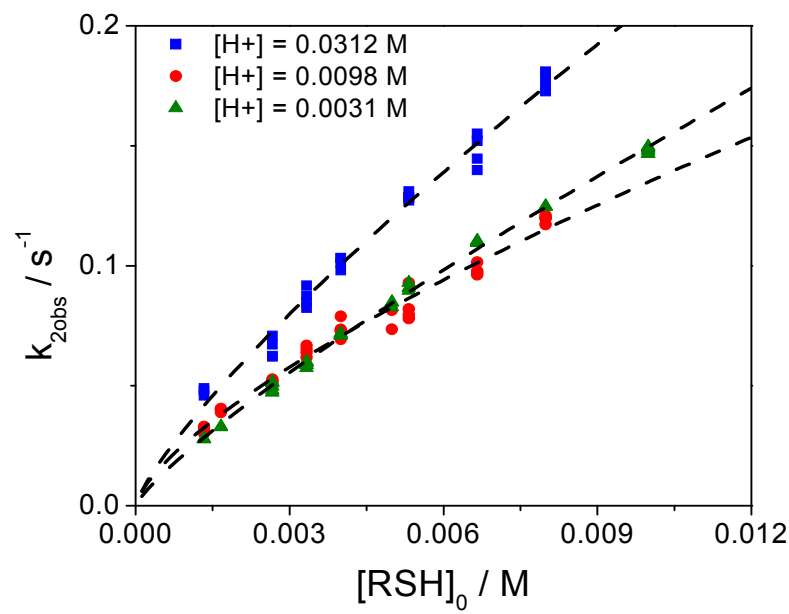

Figure 8. Dependence of $\mathrm{k}_{20 b s}$ on the thiolactic acid concentration.

Equation (17) also stipulates a slope and an intercept of the form: 
Slope $=k_{2}^{H}\left[H^{+}\right] \frac{\alpha[R S H]}{1+\beta[R S H]}(20) \quad$ Intercept $=k_{2}^{0} \frac{\alpha[R S H]}{1+\beta[R S H]}$

Once again, lines of declining slopes were obtained when plotting the intercepts and the slopes in Figure 7 against the concentration of thiolactic acid, thus giving further support to the rate equation (17).

\section{lonic strength effect}

The increase of ionic strength showed no effect on the formation of the thioester, while it slightly diminished the rate of its consumption. This is in agreement with the involvement of a neutral molecule in building of the intermediate, and some interaction of particles with opposite charges in its decomposition by a redox process.

\section{Determination of activation energies}

Because of the complexity of the system, only experimental activation energies could be determined with our data from the dependence of either $\mathrm{k}_{1 \mathrm{obs}}$ or $\mathrm{k}_{2 \mathrm{obs}}$ with temperature. Seven temperatures, between 280 and $315 \mathrm{~K}$, were used at five perchloric acid concentrations. The Arrhenius plots obtained had $R^{2}$ between 0.990 and 0.997 . Their results are given in Table 3 . The small activation energies for the electron transfer decay suggest the presence of one or more exothermal equilibria, which sustain energetically the two reaction steps.

Table 3. Experimental activation energies (each number has an error of less than $2 \%$ ).

\begin{tabular}{|c|c|c|}
\hline \multirow{2}{*}{$10^{2}\left[\mathrm{H}^{+}\right](\mathrm{M})$} & \multicolumn{2}{|c|}{$E_{\mathrm{a}}(\mathrm{kJ} / \mathrm{mol})$} \\
\hline 5.0 & Intermediate formation & Redox process \\
\hline 3.2 & 33.5 & 34.1 \\
\hline 2.0 & 35.6 & 36.4 \\
\hline 1.0 & 34.6 & 35.3 \\
\hline 0.63 & 34.9 & 35.2 \\
\hline 0.31 & 33.5 & 33.9 \\
\hline Mean: & 33.5 & 33.6 \\
\hline
\end{tabular}




\section{Extra-kinetic investigations}

The complexity of the system required some non-kinetic information in order to suggest a reaction mechanism. The literature mentions the implication of thiyl radicals in the majority of thiol oxidation reactions $[6,10,29]$. Therefore, we used the system to initiate the polymerization of methyl methacrylate. An increase in temperature of 1 to $1.2^{\circ} \mathrm{C}$ was measured as compared to the reacting system without monomer in a small calorimeter. The concentrations were as in the kinetic runs. At the end of the process, some polymer was isolated.

ESR spectra were also recorded in order to identify paramagnetic species such as $\mathrm{Cr}(\mathrm{V})$ and thiyl or other organic radicals. The obtained results were compared to $g$ values given in the literature [29]. Working in a flow system, with $[\mathrm{Cr}(\mathrm{VI})]_{0}=2.5 \cdot 10^{-3} \mathrm{M}$ and $[\mathrm{RSH}]_{0}=1.5 \cdot 10^{-2} \mathrm{M}$, the spectra presented in Figure 9 were obtained.

The species were assigned based on their $g$ values: $g=1.985$ and $\mathrm{g}=1.988$ were specific to oxo-complexes of $\mathrm{Cr}(\mathrm{V})$, and $\mathrm{g}=2.002$ to an organic radical. It should be noted that the two parts of the spectrum shown in Figure 9 were recorded using different amplification settings of the ESR spectrometer.

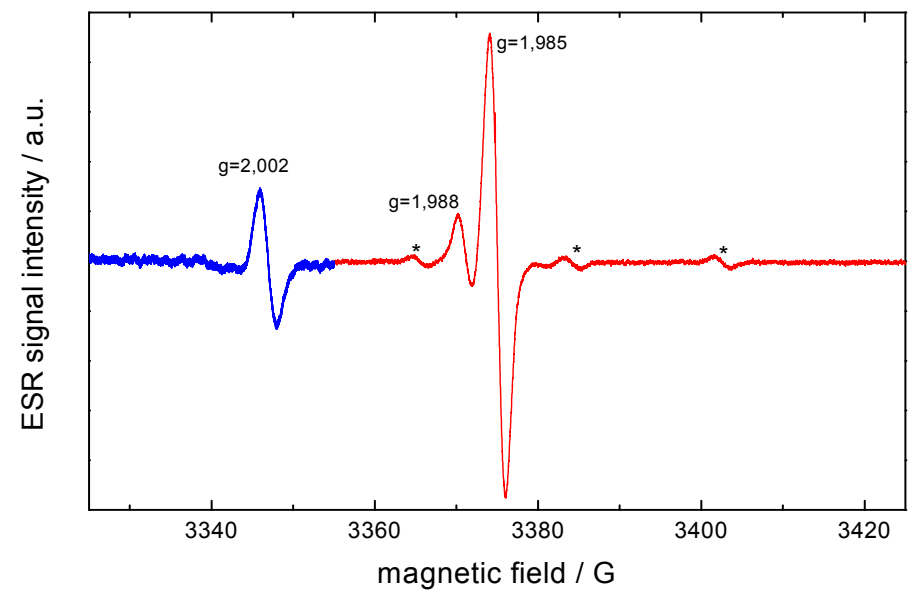

Figure 9. Paramagnetic intermediates: $\mathrm{Cr}(\mathrm{V})$ (red) and organic radical (blue). Signals marked with* are ${ }^{53} \mathrm{Cr}$ satellites of the main signal at $\mathrm{g}=1.985$. The last of the four expected lines overlaps with the signal of the organic radical at $g=2.002$.

In a stopped flow variant, at $\mathrm{g}=1.985$ and $\mathrm{g}=2.002$ kinetic curves were recorded taking the normalized intensity of the signals, as presented in Figure 10. They can only be interpreted in a qualitative manner.

It is of note that $\mathrm{Cr}(\mathrm{V})$ is not an extremely active species toward the substrate; its lifetime is rather long. The signals for $\mathrm{Cr}(\mathrm{V})$ and the organic radical behave in a similar fashion. However, the occurrence of the maximum 
of the organic radical at a slightly later time than that of the $\mathrm{Cr}(\mathrm{V})$ might be explained by one of the following two things: that $\mathrm{Cr}(\mathrm{V})$ is formed in a previous step than the organic radical, or that the organic radical might be formed together with $\mathrm{Cr}(\mathrm{V})$, but more is added as a result of $\mathrm{Cr}(\mathrm{V})$ own reduction, probably in a fashion similar to the reduction of $\mathrm{Cr}(\mathrm{VI})$.

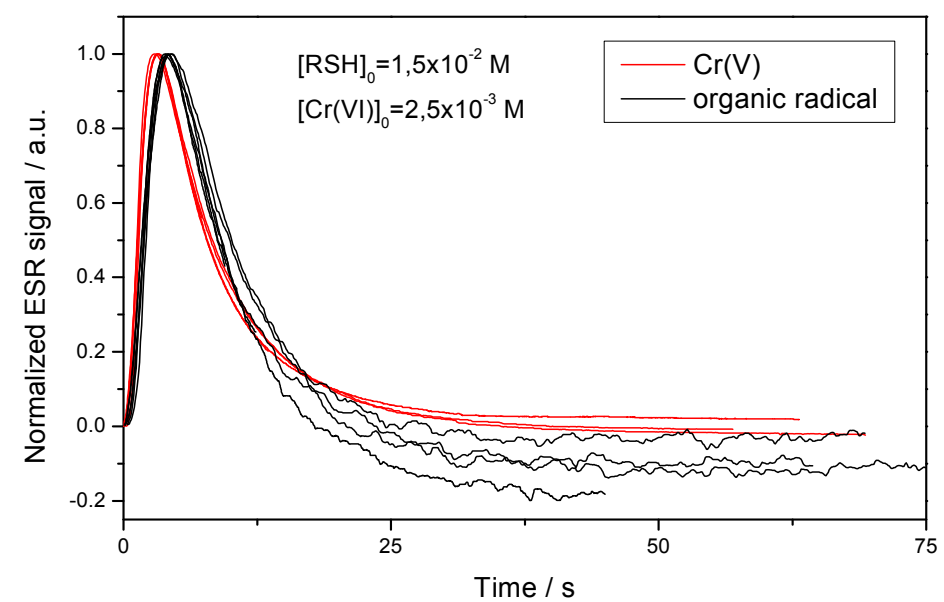

Figure 10. Kinetic curves for the paramagnetic intermediates observed during the reaction.

\section{Reaction mechanism}

Based on the kinetic and extra-kinetic results presented, the following networks of reactions seem most probable:

$$
\begin{array}{ll}
\mathrm{RSH}+\mathrm{HOCrO}_{3}{ }^{-} \rightleftharpoons \mathrm{RSCrO}_{3}{ }^{-}+\mathrm{H}_{2} \mathrm{O} & \mathrm{k}_{1}^{0}, \mathrm{k}_{-1}^{0}, \quad \mathrm{~K}_{\mathrm{f}} \\
\mathrm{RSH}+\mathrm{HOCrO}_{3}{ }^{-}+\mathrm{H}^{+} \rightleftharpoons \mathrm{RSCrO}_{3}{ }^{-}+\mathrm{H}_{3} \mathrm{O}^{+} & \mathrm{k}_{1}^{\mathrm{H}} \mathrm{k}_{-1}^{\mathrm{H}}, \quad \mathrm{K}_{\mathrm{f}} \\
\mathrm{RSCrO}_{3}{ }^{-}+\mathrm{RSH} \longrightarrow \mathrm{Cr}(\mathrm{IV})+\mathrm{RSSR} & \mathrm{k}_{21} \\
\mathrm{RSCrO}_{3}{ }^{-}+\mathrm{RSH}+\mathrm{H}^{+} \longrightarrow \mathrm{Cr}(\mathrm{IV})+\mathrm{RSSR} & \mathrm{k}_{22}
\end{array}
$$

No precise affirmation can be made on the successive steps following the rate-determining ones. To get the correct stoichiometry, $\mathrm{Cr}(\mathrm{IV})$ species should react further to form final products and generate $\mathrm{Cr}(\mathrm{V})$. The processes are characterized by higher rate constants and take place as fast as the corresponding intermediate species are formed, with the exception of (28).

$$
\begin{aligned}
& \mathrm{Cr}(\mathrm{IV})+\mathrm{RSH} \longrightarrow \mathrm{Cr}(\mathrm{III})+\mathrm{RS}^{\bullet} \quad \text { fast } \\
& \mathrm{Cr}(\mathrm{IV})+\mathrm{Cr}(\mathrm{VI}) \rightleftharpoons 2 \mathrm{Cr}(\mathrm{V}) \\
& \mathrm{Cr}(\mathrm{V})+2 \mathrm{RSH} \longrightarrow \mathrm{RSSR}+\mathrm{Cr}(\mathrm{III})
\end{aligned}
$$


If sequence 24-28 was operative, under excess of $\mathrm{RSH}$ it seems likelier that the $\mathrm{RS}^{\bullet}$ should be formed before $\mathrm{Cr}(\mathrm{V})$, which contradicts the information in Figure 10.

An alternative and kinetically indistinguishable reaction sequence, with the rate determining steps as one-equivalent electron transfer and the formation of $\mathrm{Cr}(\mathrm{V})$ and a disulfide ion radical, is:

$$
\begin{array}{ll}
\mathrm{RSCrO}_{3}{ }^{-}+\mathrm{RSH} \longrightarrow \mathrm{Cr}(\mathrm{V})+\mathrm{RSSR}^{-\bullet} & \mathrm{k}_{21}{ }^{\prime}, \\
\mathrm{RSCrO}_{3}{ }^{-}+\mathrm{RSH}+\mathrm{H}^{+} \longrightarrow \mathrm{Cr}(\mathrm{V})+\mathrm{RSSR}^{-} & \mathrm{k}_{22}{ }^{\prime}
\end{array}
$$

The disulfide radical anion is a species with an electron in the antibonding S-S link, first evidenced by $\beta$ ray bombardment of thiol solutions [30] and is much more stable as compared to the thiyl radical. Using MO calculations, formation enthalpies of $-1064 \mathrm{~kJ} / \mathrm{mol}$ for $\mathrm{RSSR}^{-\bullet}$ and -268 $\mathrm{kJ} / \mathrm{mol}$ for RS ${ }^{\bullet}$ were computed. Based on this and on the fact that, while not necessarily supported by the interpretation of Figure 10, it is also not contradicted by it, we incline to consider this way as being operative. Another argument in its favor is that an order superior to one and a one-plus type rate law has been found by us at the oxidation of thiolactic acid by hexacyanoferrate (III), which is a one-equivalent oxidizing agent [31].

However, the rate law deduced from each of the two variants of the mechanism, with either (24-25) or (29-30) steps as rate determining, is:

$$
-\frac{d\left[\mathrm{HCrO}_{4}^{-}\right]}{d t}=\frac{k_{21} K_{f}[\mathrm{RSH}]^{2}}{1+K_{f}[\mathrm{RSH}]}\left[\mathrm{HCrO}_{4}^{-}\right]+\frac{k_{22} K_{f}[\mathrm{RSH}]^{2}\left[\mathrm{H}^{+}\right]}{1+K_{f}[\mathrm{RSH}]}\left[\mathrm{HCrO}_{4}^{-}\right]
$$

in agreement with the experimental one.

\section{CONCLUSIONS}

The reaction between thiolactic acid (RSH) and chromium ( $\mathrm{VI})$ proceeds via the formation of an intermediate of esteric type, evidenced by spectral data. The reaction orders for both the formation and decay of the intermediate have been assessed, with respect to the species participating in each step, respectively.

For both $\mathrm{RSH}$ and $\mathrm{HCrO}_{4}-$ reaction orders of 1 have been found for the first step, indicating a 1:1 composition of the intermediate complex. In acidic environment, two parallel paths are available for the intermediate formation: not assisted or assisted by one hydrogen ion.

A first order has been found with respect to the thioester for its decay in an electron transfer path, and a fractional one, between 0 and 1 with thiolactic acid. Since the thioester already contains one substrate molecule, 
by means of the pre-equilibrium of its formation, the overall reaction order for the thiolactic acid is between 1 and 2. The two parallel paths, involving or not the $\mathrm{H}^{+}$continue to be operative.

Taking into account all these, the extra-kinetic proofs of $\mathrm{Cr}(\mathrm{V})$ and of free radicals, as well as the stoichiometry, it was possible to advance a reaction mechanism which gives rise to a rate law in accordance with all these features.

\section{EXPERIMENTAL SECTION}

All chemicals employed in the study were of certified analytical reagent grade from commercial sources, and used without further purification. The solutions were prepared in demineralised and tetra-distilled water. Stock solutions of $\mathrm{HClO}_{4}$ and $\mathrm{NaClO}_{4}$ were prepared and standardised by titration with a $\mathrm{NaOH}$ solution of known factor. Aliquots of the $\mathrm{NaClO}_{4}$ solution were passed over a cationic resin Virolyte $\mathrm{C}-100$ (Victoria, Romania) in the H-form, and then the resulted acid was titrated. The solution of thiolactic acid was freshly prepared and standardised iodometrically before each set of runs.

The course of the reaction was followed spectrophotometrically under static conditions at $420 \mathrm{~nm}$, by using a Jasco V-530 spectrophotometer interfaced to a computer for data acquisition and equipped with a cell holder connected to a thermostat. A 5-cm path length quartz cuvette has been used. The process was initiated by injecting $1 \mathrm{ml}$ of thermostated chromic acid solution directly into the cell, over the mixture of the other reactants. The mixing time did not exceed 1 second. The use of a calibrated syringe with a fine needle was required in order to ensure an appropriate mixing upon injection; this made some turbulence unavoidable and the first 1-3 seconds of the data recording not entirely reproducible.

Three to seven replicate runs were performed for each set of experimental conditions. These conditions usually involved $\mathrm{T}=293 \pm 0.1 \mathrm{~K}$, $\mu=0.5 \mathrm{M}\left(\mathrm{NaClO}_{4}\right), \mathrm{Cr}(\mathrm{VI})$ always as the limiting reactant $\left(6.67 \cdot 10^{-5} \mathrm{M}\right)$ and $\mathrm{RSH}$ and $\mathrm{H}^{+}$in high enough excess so that their concentrations could be considered with good approximation invariable. A few lower excesses were used as well in the case of $\mathrm{RSH}$, in an attempt to enlarge the range of concentrations tested and since at higher excesses the reaction became too fast to follow for batch conditions. The range of concentrations spanned was $1.33 \cdot 10^{-3}$ to $9.99 \cdot 10^{-3} \mathrm{M}$ for RSH and $1.3 \cdot 10^{-3}$ to $9.84 \cdot 10^{-2} \mathrm{M}$ for $\mathrm{H}^{+}$.

The stoichiometry of the process was determined first by means of spectrophotometrical titration. Various mixtures, with initial known molar ratio were allowed to react to completion (at least 8 half-lives) at room temperature, constant acidity of $0.01 \mathrm{M}$ and constant ionic strength of $0.5 \mathrm{M}$. 
The measurements were done at $350 \mathrm{~nm}$. To make sure that the completion has been reached, the mixtures were tested both after 3 and after 10 hours, with similar results. The final absorbance values were measured and compared to the one obtained with a solution containing all reactants, except for the thiolactic acid. Several experiments were made involving iodometrical titration of the remaining substrate. Six mixtures were allowed to react under excess $\mathrm{RSH}$ and $\mathrm{H}^{+}$conditions similar to the smallest ones used in the kinetic runs, but with all the concentrations being 10 times higher. In such case, the reaction had reached completion already during the mixing of the reactants. Nevertheless, the mixtures were then set to rest for about half an hour, after which the remaining thiolactic acid was titrated iodometrically. For comparison, six blank solutions (containing $\mathrm{RSH}$ but not $\mathrm{Cr}(\mathrm{VI})$ ) were treated in a similar fashion and titrated as well.

Using the system to initiate polymerisation of methyl methacrylate and measuring the temperature increase in a small calorimeter, the involvement of free radicals was checked.

Also, ESR studies were made, under static or dynamic regime to detect and monitor paramagnetic species as $\mathrm{Cr}(\mathrm{V})$ or organic free radicals.

\section{ACKNOWLEDGMENTS}

The authors would like to thank Prof. G. Grampp, Institute of Physical and Theoretical Chemistry, Graz University of Technology, Austria, for providing access to the ESR facility and Dr. K. Rasmussen, European Space Research and Technology Centre, European Space Agency, Netherlands, for insight on the ESR data.

\section{REFERENCES}

1. V. Bianchi, A. G. Lewis, Toxicological \& Environmental Chemistry, 1987, 15, 1.

2. P. H. Connett, K. E. Wetterhahn, "Metabolism of the carcinogen chromate by cellular constituents", In: Inorganic Elements in Biochemistry. Structure and Bonding, Springer-Verlag, Berlin, Heidelberg, 1983, 54, 93.

3. M. D. Cohen, B. Kargacin, C. B. Klein, M. Costa, Critical Reviews in Toxicology, 1993, 23, 255.

5. S. Mishra, R. N. Bharagava, Journal of Environmental Science and Health, Part C, 2016, 34, 1.

4. R. Saha, R. Nandi, B. Saha, Journal of Coordination Chemistry, 2011, 64, 1782.

6. I. Bâldea, D.-M. Sabou, Studia Universitatis Babeş-Bolyai, Chemia, 2001, 46(12), 17 and references therein. 
7. U. Kläning, M. C. R. Symons, Journal of the Chemical Society, 1961, 3204.

8. N. Bailey, A. Carrington, K. A. K. Lott, M. C. R. Symons, Journal of the Chemical Society, 1960, 290.

9. M. Cohen, F. H. Westheimer, Journal of the American Chemical Society, 1952 , 74, 4387.

10. A. McAuley, M. A. Olatunji, Canadian Journal of Chemistry, 1977, 55, 3328; ibid., 1977, 55, 3335.

11. G. P. Haight, E. Perchonock, P. Emmenegger, G. Gordon, Journal of the American Chemical Society, 1965, 87, 3835.

12. K. B. Wiberg, H. Schäfer, Journal of the American Chemical Society, 1969, 91, 933.

13. J. H. Espenson, Accounts of Chemical Research, 1970, 3(10), 347.

14. V. P. Roldán, V. A. Daier, B. Goodman, M. I. Santoro, J. C. González, N. Calisto, S. R. Signorella, L. F. Sala, Helvetica Chimica. Acta, 2000, 83, 3211.

15. D. A. Dixon, N. P. Sadler, T. P. Dasgupta, Journal of the Chemical Society, Dalton Transactions, 1993, 23, 3489.

16. G. P. Haight, G. M. Jursich, M. T. Kelso, P. J. Merill, Inorganic Chemistry, 1985, 24, 2740.

17. J. F. Perez-Benito, C Arias, R. M. Rodriguez, Journal of Physical Chemistry A, 2001, 105, 1150.

18. S. Signorella, M. I. Frascaroli, S. García, M. Santoro, J. C. González, C. Palopoli, V. Daier, N. Casado, L. F. Sala, Journal of the Chemical Society, Dalton Transactions, 2000, 1617.

19. S. N. Mahapatro, M. Krumpolc, J. Roček, Journal of the American Chemical Society, 1980, 102, 3799.

20. P. Subramaniam, N. T. Selvi, American Journal of Analytical Chemistry, 2013, 4, 20.

21. D. C. Ramdon, D. A. Dixon, T. P. Dasgupta, Inorganic Reaction Mechanisms, 2004, 5(3), 1.

22. D.-M. Sabou, Studia Universitatis Babeş-Bolyai, Chemia,, 2014, 59(4), 183.

23. J. Y. Tong, E. L. King, Journal of the American Chemical Society, 1953, 75, 6180.

24. N. N. Greenwood, A. Earnshaw, "Chemistry of the Elements", 2. Edition, Butterworth-Heinemann, Oxford, UK, 1997, chapter 23.

25. D.-M. Sabou, A. Csavdári, Muszaki Szemle (Tehnical Review), 2015, 66, 26.

26. T. Carrington, International Journal of Chemical Kinetics, 1982, 14(5), 517.

27. I. Bâldea, D.-M. Sabou, A. Csavdari, Studia Universitatis Babeş-Bolyai, Chemia, 2007, 52(1), 19.

28. A. Csavdári, I. Bâldea, D.-M. Sabou, Studia Universitatis Babeş-Bolyai, Chemia, 2007, 52(3), 113.

29. A. Levina, L. Zhang, P. A. Lay, Journal of the American Chemical Society, 2010, 132,8720 and references therein.

30. Z. M. Hoffman, E. Hayon, Journal of the American Chemical Society, 1972, 94(23), 7950.

31. I. Bâldea, D.-M. Sabou, A Csavdári, Revue Roumaine de Chimie, 2009, 54(10), 791. 